\title{
DINOSAUR TRACKS AS PATHWAYS TO PARKS, PUBLIC EDUCATION, AND CONSERVATION PROJECTS
}

LOCKLEY*, Martin, Department of Geology, University of Colorado at Denver, P.O. Box 173364, Denver CO 80217-3364, U.S.A.

It is not only dinosaur skeletal remains that attract great public attention. In recent years much interest has been generated in tracks, eggs, nests, and even coprolites. Tracks are arguably the most abundant of any form of vertebrate evidence. Large tracksites, however, cannot be excavated and transported to museums; they must be studied in situ. In recent years many tracksites around the world have been developed as outdoor interpretive sites. Examples from North America include: Dinosaur State Park, Connecticut; Dinosaur Valley State Park, Texas; Dinosaur Ridge, Colorado; the Purgatoire Valley, Colorado; and Clayton Lake State Park, New Mexico. Guidebooks exist to help visitors interpret several of these sites. The Texas site is purported to reveal controversial evidence of a predator attacking prey, and the Purgatoire site, frequently photographed, reveals parallel trackway evidence of herd behavior.

At Carenque, a suburb of Lisbon, Portugal, one of the world's longest dinosaur trackways $(141 \mathrm{~m})$ was recently saved from destruction by a freeway construction project through the intervention of the government (President) and the construction of an 8 million dollar tunnel beneath the site. The site will become a public park and is already the subject of an entire book that details the "battle" to save the trackways.

Elsewhere in Europe, tracksites have been developed into outdoor interpretive sites in Germany (at Barkhausen and Münchehagen), in Switzerland (at Lommiswil), in Italy (at Lavini de Marco), and there are many sites open to the public in the La Rioja region of Spain. In the latter region, an extensive network of tracksites has been developed into an ichnological trail named "Ruta de icnitas" and many sites are well documented in an impressive guidebook

In East Asia, the Nakasato Dinosaur Center (Sebayashi region of Japan) was built around controversial indentations purported to be dinosaur tracks. In South Korea, abundant dinosaur tracks occur in coastal exposures within the Hallyo Haysang National Park area near Samcheonpo. The area has achieved national fame and has been featured in Korea's leading magazines and on national television. Similarly, Lark Quarry in Australia's outback is nationally and internationally know as a result of media coverage discussing purported evidence of a large carnivore attacking smaller prey.

Tracks have sometimes been the target of commercial and amateur collectors though, usually, they are not considered as attractive as skeletal remains. In the United States at least one case of vandalism is under investigation by the FBI; unique material (now type specimens) were removed with dynamite and rocksaws from an Indian Reservation. 